\title{
Late-Life Body Mass Index and Dementia: An Integrative Literature Review
}

\author{
Sarah Slade
}

Patricia K. Ravert

Brigham Young University - Provo, patricia-ravert@byu.edu

Follow this and additional works at: https://scholarsarchive.byu.edu/facpub

Part of the Geriatric Nursing Commons, and the Other Nursing Commons

\section{Original Publication Citation}

Slade, S. J. \& Ravert, P. (2012). Late-life body mass index and dementia: An integrative literature review. Journal of the American Academy of Nurse Practitioners. 8(9), 725-728.

\section{BYU ScholarsArchive Citation}

Slade, Sarah and Ravert, Patricia K., "Late-Life Body Mass Index and Dementia: An Integrative Literature Review" (2012). Faculty Publications. 5278.

https://scholarsarchive.byu.edu/facpub/5278

This Peer-Reviewed Article is brought to you for free and open access by BYU ScholarsArchive. It has been accepted for inclusion in Faculty Publications by an authorized administrator of BYU ScholarsArchive. For more information, please contact ellen_amatangelo@byu.edu. 


\title{
Late-Life Body Mass Index and Dementia: An Integrative Literature Review
} Sarah Slade, RN, FNP, and Patricia (Patty) Ravert, PhD, RN

\begin{abstract}
Dementia and obesity are significant public health concerns. Alzheimer's disease affects 5.3 million adults, while 72.5 million adults are obese. Emerging evidence linking body mass index (BMI) and dementia suggest that, although a high BMI in midlife is associated with a greater risk for dementia, a high BMI in late life is considered protective and should not necessarily be considered a risk factor for dementia. Beginning in midlife, practitioners should trend patient BMI numbers. Major fluctuations during this time should be monitored and nutritional counseling and cognitive screenings offered to help patients maintain a healthy BMI and detect early cognitive decline.
\end{abstract}

Keywords: Alzheimer's, body mass index, dementia, late life, midlife obesity (C) 2012 American College of Nurse Practitioners

Table 1 is available at www.npjournal.org.

$\mathrm{N}$ urse practitioners (NPs) are aware of the growing incidence of both dementia and obesity in our society but may not be aware of their association. Practitioners counsel patients to keep a low or normal body mass index (BMI) to avoid chronic diseases such as diabetes and cardiovascular problems. However, new evidence shows that while this counsel is appropriate for patients in midlife, practitioners need to be aware that an increased BMI in late life may actually be protective against dementia. ${ }^{1-11}$

This article answers the question of whether late-life patients (65 years or older) who have high BMI ( $\geq 25)$ are at increased risk for dementia compared with midlife patients (30-64) who also have a high BMI. Understanding the association between BMI and the possible risks for or prevention of dementia will change the way NPs treat and counsel on BMI in the elderly.

\section{BACKGROUND AND SIGNIFICANCE}

Dementia is a classification for a group of fatal neurological diseases manifested by a decline in memory and intellectual functioning that interferes with daily life and relationships. ${ }^{12}$ Dementia damages brain cells, which results in memory impairment and causes an inability to understand and respond to language, identify objects, and complete activities of daily living. According to the Alzheimer's Association, ${ }^{13}$ there are several types of dementia: Alzheimer's disease (AD), vascular dementia, mixed dementia, dementia with Lewy bodies, Parkinson's disease, fron- totemporal dementia, Creutzfeldt Jakob disease, normal pressure hydrocephalus, and mild cognitive impairment.

$\mathrm{AD}$ is the most prevalent form of dementia and accounts for $60 \%-80 \%$ of the cases. ${ }^{13}$ An estimated 5.3 million Americans have $\mathrm{AD}$, and the incidence is expected to increase to 16 million by $2050 .{ }^{14}$ This disease is a result of the failure of neurons to transfer information at the synapses and leads to cellular shrinkage and death. The exact reason for this failure has yet to be discovered, but advancing age is 1 of the greatest risk factors. ${ }^{15}$ Other risk factors, such as type 2 diabetes, hyperlipidemia, tobacco use, genetics, an inherited apolipoprotien ApoE-e4, and obesity, have been associated with dementia. ${ }^{15}$

$\mathrm{AD}$ affects each person differently but usually begins with such symptoms as a gradual difficulty in remembering new information, confusion with time or place, and difficulty completing familiar tasks at home or work. Once the disease has advanced into the final stages, patients require total care. Patients eventually lose their ability to recognize and communicate with family and friends and become confined to bed. Because of the extensive care needed throughout the course, especially in the final stages, the total costs for those who suffer from this disease are 3 times higher than for non-affected older people. The cost of AD care reaches $\$ 172$ billion annually. ${ }^{15}$

According to the Alzheimer's Association, ${ }^{15}$ there is no known treatment to stop or slow the degeneration of brain cells for any type of dementia. Five drugs have been 
approved to temporarily slow degeneration, but they are effective only for half of the prescribed patients and usually only for 6 to 12 months. Since the neurological system and cardiovascular system are closely intertwined, the management of cardiovascular risk factors is important.

Managing type 2 diabetes, hyperlipidemia, hypertension, tobacco use, and obesity might help delay the cognitive impairment associated with dementia. ${ }^{15}$

Obesity affects 72.5 million Americans and is considered a risk factor for dementia. ${ }^{15,16}$ The BMI scale is a screening tool to determine different weight categories that may lead to such health problems as AD. This scale uses weight in kilograms divided by the square of the height in meters $\left(\mathrm{kg} / \mathrm{m}^{2}\right)$. According to this scale, obesity is $\mathrm{BMI} \geq 30.0$, overweight is BMI of 25.0-29.9, normal weight BMI of 18.5-24.9, and underweight $\mathrm{BMI}<18.5$. A BMI $>25$ has been shown to increase the chances of certain diseases and other health problems. ${ }^{13,17}$

Although recent studies ${ }^{18-21}$ have shown that an increased BMI in midlife (30-64) can lead to an increase in dementia, other studies ${ }^{1-11}$ have indicated an increased BMI in late life (65 or older) is protective of these neurological impairments. Additional evidence suggests that a low or underweight BMI or fast declining BMI is a preclinical marker for dementia. ${ }^{1,2,22-25}$ Understanding the patterns linking BMI and dementia is important to practitioners to assist in treating and counseling patients in slowing the progression of dementia. The purpose of this integrative review is to examine and discuss the implications associated with late-life BMI and dementia.

\section{METHODS}

An electronic search was conducted to identify studies from 2005 to 2010 using the following databases: EBSCO, CINAHL, Medline, and Health Source: Nursing/Academic Edition. The search was limited to the English language and human subjects. The search terms used were body mass index, dementia, midlife, late-life, and aged.Articles focusing solely on midlife BMI were excluded, whereas articles focusing on midlife and latelife BMI and dementia were included. References from all articles were reviewed for additional relevant studies.

\section{RESULTS}

\section{Study Characteristics}

A total of 13 studies were evaluated (Table online). Ten of the studies ${ }^{1-9,11}$ were population-based prospective cohort studies, 1 study was case controlled, ${ }^{26}$ and 2 were cross-sectional studies. ${ }^{10,27}$ Follow-up time in the cohort studies ranged from 1 to 13.4 years. The number of participants in the studies ranged from 50 to 12,047 . The studies were conducted in various locations- 6 in the United States ${ }^{2,3,5,7-9}$ and 7 in other countries. 1,4,6,10,11,26,27

All studies in the review used BMI as 1 of the main anthropometric measurements. In addition to BMI, 5 studies used waist-to-hip ratio (WHR), ${ }^{5-7,11,26} 5$ studies used waist circumference (WC), ${ }^{6,7,9-11}$ and 1 study included percentage of body fat (PBF). ${ }^{6}$

\section{Participant Characteristics}

The age of participants included in the studies ranged from 60 to 101 years. Twelve studies included male and female participants, ${ }^{1-10,26,27}$ with 1 study only including male participants. ${ }^{11}$

\section{Anthropometric Measures}

Reviewing studies that included WHR, PBF, and WC yielded varied outcomes. In the 5 studies that examined WHR in addition to BMI, 2 reported no correlation between WHR and any form of dementia, ${ }^{5,7}$ while 1 reported that men with WHR $\geq 0.9$ had a lower risk of dementia than men with WHR $<0.9$. One study concluded participants who were obese at the time of the baseline WHR assessment and had a decreased WHR over time reported a decline in cognitive function, ${ }^{6}$ and 1 study reported an increased WHR more than doubled the risk of $\mathrm{AD} .^{26} \mathrm{Han}$ et $\mathrm{al}^{6}$ also looked at PBF and concluded that, like BMI, a higher PBF was associated with a decreased risk of dementia.

The 5 studies that included WC also yielded varied outcomes. Two studies reported no relationship between WC and dementia. ${ }^{7,10}$ One study concluded there was a U-shaped correlation between WC and dementia, with the risk being the greatest at both the lower and upper ends of the WC measurements, ${ }^{6}$ and 1 study reported the lowest risk of dementia was around $100 \mathrm{~cm}$ of WC. ${ }^{11}$ The researchers of the fifth study initially found no association between WC and dementia risk, but after adjusting for BMI and excluding previous dementia cases included in the study, they reported a $29 \%$ increase in the hazard ratio (HR), indicating the highest WC led to a higher risk for dementia. ${ }^{9}$ 


\section{CLINICAL FINDINGS}

All 10 of the population-based, prospective, cohort studies concluded an increased BMI in late life was protective of dementia (Table 1). ${ }^{1-9,11}$ One study reported that for each 1 unit increase in BMI from the patient's baseline, the risk of dementia decreased $8 \% .{ }^{4}$ Another study reported that each 1 unit increase of BMI from baseline was associated with more than 5\% decrease in the risk of $\mathrm{AD}$ and a loss of 1 unit of BMI from baseline per year was associated with about a $25 \%$ increased risk of AD compared with a person experiencing no change in BMI. ${ }^{2}$ Furthermore, another study reported overweight participants had a lower risk of developing dementia than normal-weight participants over a 9-year time span. Underweight participants also increased their risk of developing dementia by $20 \%{ }^{1}$

Razay et al's ${ }^{26}$ case-controlled study produced opposite findings, suggesting an increased BMI is associated with an almost 10-fold increase in AD risk in later life. However, this study also found being underweight was associated with an almost 8 -fold increase in AD risk. The findings from this study suggest that both obesity and being underweight may be associated with AD. ${ }^{26}$

Results from the 2 cross-sectional studies varied. Zhou et $\mathrm{al}^{27}$ specifically reported that in Chinese subjects $\geq 90$, a BMI in the normal range, around 20 (18.9-21.1), was most protective of dementia. Ghaderpanahi et al ${ }^{10}$ agreed with all 10 of the population-based, prospective, cohort studies that having an increased BMI in later life is protective of dementia.

\section{DISCUSSION}

All 10 studies indicated an increased BMI ( $\geq 25$ ) in later life protects against dementia. These results differ from studies conducted in midlife (30-64 years old) that report an increased BMI during this time is a major risk factor for dementia. ${ }^{18-21}$ However, 1 study concluded that dementia is associated with a lesser increase in BMI from age $38-70$ in women. ${ }^{28}$ Studies from both midlife and late life agree that a decreasing BMI or weight loss in late life may precede the diagnosis of dementia and potentially be a preclinical marker for AD. .,2,22-25 $^{2}$

The factors associated with weight loss and dementia in the elderly are poorly understood. Memory impairment as an initial symptom could cause forgetfulness and loss of initiative, leading to weight loss and malnutrition. ${ }^{4,22}$ Other researchers suggest atrophy of the medial temporal lobe, hippocampal formation, and hypometabolism of the cingulate gyrus. This atrophy disrupts hypothalamic and autonomic regulation, affecting appetite and energy metabolism. ${ }^{2}$ Gustafson $^{22}$ suggests that hormones released by different organs and tissues, as well as the release of neuropeptides, can interact with brain centers to induce physiological responses associated with weight reduction before the onset of dementia. This deregulation of brain centers can lead to poor eating and metabolism regulation.

While understanding the relationship between weight loss and dementia is important, understanding why an increased BMI in late life is protective of cognitive decline is also valuable. Some researchers suggest that higher weight in late life increases insulin-like growth factor-I (IGF-I), ${ }^{29}$ leptin, ${ }^{30}$ and estrogen ${ }^{31}$ levels. All 3 of these hormones are released from adipose cells. IGF-I aids in neuronal growth, balances neuronal excitability, and maintains synaptic plasticity. ${ }^{29}$ Leptin influences hippocampal-dependent learning and memory and regulates hippocampal excitability, ${ }^{30}$ whereas estrogen protects mitochondria from injury and cellular death. ${ }^{31}$

Researchers hypothesize these hormonal processes may explain the relation between a higher weight and better cognitive function and more research is necessary to determine correlations.

\section{RECOMMENDATIONS}

In clinical settings, beginning in midlife, practitioners should determine the patient's BMI at each visit and track weight loss and gain. If a patient's BMI in midlife increases, nutritional counseling and exercise recommendations should be given to help the patient return to a healthy weight and thus prevent the risk of dementia in late life. A high BMI, representing overweight and obesity, in late life should not be considered a risk factor for dementia. However, an unintentional loss in BMI moving toward underweight (18.5) should be considered a warning sign. If this reduction in BMI is discovered, cognitive screenings, such as the Mini-Mental State Examination or the Clinical Dementia Rating Scale, should be administered to give practitioners a cognitive baseline. Nutritional counseling involving the patient and family or caregiver should also be implemented to assist the patient in returning to a healthy and higher BMI and help minimize further declines in cognitive status. 


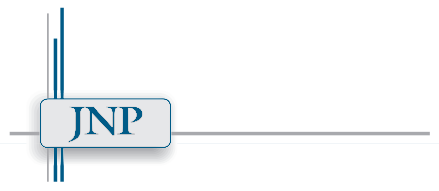

Although the evidence presented in this article suggests that higher BMI in late life will decrease the risk of dementia, a high BMI is also associated with other medical disorders, such as cardiovascular disease, hypertension, and diabetes. ${ }^{13,32}$ Practitioners working with this late-life population must assess patient and family history and determine which risks are greater to overall health. For a patient with a family history of dementia, keeping the patient's BMI above the normal level should be considered.

\section{CONCLUSION}

Although a high BMI $(\mathrm{BMI} \geq 25)$ in midlife is associated with a greater risk for dementia, current evidence shows that higher BMI, per unit, in late life is considered protective for cognitive impairments and should not be considered a risk factor for dementia. Additional evidence suggests a low or underweight BMI $(\leq 18.5)$ or fast declining BMI is a preclinical marker for dementia. JNP

\section{References}

1. Atti AR, Palmer K, Volpato $S$, et al. Late- life body mass index and dementia incidence: nine-year follow-up data from the Kungsholmen project. $J$ Am Geriatr Soc. 2008;56(1):111-116.

2. Buchman AS, Wilson RS, Bienias JL, et al. Change in body mass index and risk of incident Alzheimer disease. Neurology. 2005;65(6):892-897.

3. Cronk BB, Johnson DK, Burns JM. Body mass index and cognitive decline in mild cognitive impairment. Alz Dis Assoc Dis. 2010;24(2):126-130.

4. Dahl AK, Löppönen $M$, Isoaho $R$, et al. Overweight and obesity in old age are not associated with greater dementia risk. J Am Geriatr Soc. 2008;56(12):2261-2266.

5. Fitzpatrick AL, Kuller LH, Lopez OL, et al. Midlife and late-life obesity and the risk of dementia: cardiovascular health study. Arch Neurol. 2009;66(3):336342.

6. Han C, Jo SA, Seo JA, et al. Adiposity parameters and cognitive function in the elderly: application of "jolly fat" hypothesis to cognition. Arch Gerontol Geriat. 2008;49(2):e133-e138.

7. Hughes TF, Borenstein AR, Schofield E, et al. Association between late-life body mass index and dementia: the Kame project. Neurology. 2009;72(20):1741-1746.

8. Sturman MT, Mendes de Leon CF, Bienias JL, et al. Body mass index and cognitive decline in a biracial community population. Neurology. 2008;70:360-367.

9. West NA, Haan MN. Body adiposity in late life and risk of dementia or cognitive impairment in a longitudinal community-based study. $J$ Gerontol ABiol Sci Med Sci. 2009;64A(1):103-109.

10. Ghaderpanahi M, Fakhrzadeh $\mathrm{H}$, Sharifi $\mathrm{F}$, et al. Association between late-life body mass index, waist circumference and dementia: Kahrizak Elderly Study. J Am Geriatr Soc. 2012;60(1):173-174.

11. Power BD, Alfonso $\mathrm{H}$, Flicker $\mathrm{L}$, et al. Body adiposity in later life and the incidence of dementia: the Health in Men Study. PLoS ONE. 2011;6(3):e17902.

12. National Institutes of Health. NINDA dementia information page. http://www.ninds.nih.gov/disorders/dementias/dementia.htm. Accessed February 5, 2012.

13. Centers for Disease Control and Prevention. About BMI for adults. http://www.cdc.gov/healthyweight/assessing/bmi/adult_bmi/index.html\#Cons equences Accessed February 6, 2012.

14. Hebert LE, Scherr PA, Bienias JL, et al. Alzheimer's disease in the U.S. population: prevalence estimates using the 2000 census. Arch Neurol. 2003;60:1119-1122.

15. Alzheimer's Association. Alzheimer's disease facts and figures 2010. http://www.alz.org/documents_custom/report_alzfactsfigures2010.pdf. Accessed February 6, 2012.

. Centers for Disease Control and Prevention. State-specific obesity prevalence among adults-United States. http://www.cdc.gov/mmwr/pdf/wk/ mm59e0803.pdf. Accessed February 6, 2012.

17. World Health Organization. Obesity and overweight. http://www.who.int/ mediacentre/factsheets/fs311/en/index.html. Accessed February 6, 2012.

18. Hassing LB, Dahl AK, Thorvaldsson V, et al. Overweight in midlife and risk of dementia: a 40-year follow-up study. Int J Obesity. 2009;33:893-898.

19. Kivipelto $M$, Ngandu T, Fratiglioni $L$, et al. Obesity and vascular risk factors at midlife and the risk of dementia and Alzheimer disease. Arch Neurol. 2005;62:1556-1560.

20. Whitmer RA, Gunderson EP, Quesenberry Jr CP, et al. Body mass index in midlife and risk of Alzheimer disease and vascular dementia. Curr Alzheimer Res. 2007;4(2):103-109.

21. Xu WL, Atti AR, Gatz M, et al. Midlife overweight and obesity increase latelife dementia risk. Neurology. 2011;76:1568-1574.

22. Gustafson D. Adiposity indices and dementia. Lancet Neurol. 2006;5:713720.

23. Stewart R, Masaki K, Xue Q, et al. A 32-year prospective study of change in body weight and incident dementia: the Honolulu-Asia aging study. Arch Neurol. 2005;62(1):55-60.

24. Gustafson DR, Backman K, Joas E, et al. 37 years of body mass index and dementia: observations from the prospective population study of women in Gothenburg, Sweden. J Alzheimers Dis. 2012; 28(1):163-171

25. Chu L, Tam S, Lee PWH, et al. Late-life body mass index and waist circumference in amnestic mild cognitive impairment and Alzheimer's disease. J Alzheimers Dis. 2009;17(1):223-232.

26. Razay G, Vreugdenhil A, Wilcock G. Obesity, abdominal obesity and Alzheimer disease. Dement Geriatr Cogn Disord. 2006;22(2):173-176.

27. Zhou Y, Flaherty JH, Huang $\mathrm{C}$, et al. Association between body mass index and cognitive functions among Chinese nonagenarians/centenarians. Dement Geriatr Cogn Disord. 2011;30:517-524.

28. Gustafson DR, Bäckman K, Waern M, et al. Adiposity indicators and dementia over 32 years in Sweden. Neurology. 2009;73:1559-1566.

29. Aleman A, Torres-Alemán I. Circulating insulin-like growth factor I and cognitive function: neuromodulation throughout the lifespan. Prog Neurobiol. 2009;89:256-265.

30. Harvey J. Leptin regulation of neuronal excitability and cognitive function. Curr Opin Pharmacol. 2007;7:643-647.

31. Simpkins JW, Dykens JA. Mitochondrial mechanisms of estrogen neuroprotection. Brain Res Rev. 2007;57:421-430.

32. Bays HE, Chapman RH, Grandy S. The relationship of body mass index to diabetes mellitus, hypertension and dyslipidaemia: comparison of data from two national surveys. Int J Clin Pract. 2007;61(5):737-774.

Sarah Slade, RN, FNP, is a nurse practitioner in Arizona and can be reached at SladeFNP@yahoo.com. Patricia Ravert, PhD, RN, CNE, ANEF, FAAN, is dean and professor at Brigham Young University's College of Nursing in Provo, UT. In compliance with national ethical guidelines, the authors report no relationships with business or industry that would pose a conflict of interest.

$1555-4155 / \$$ see front matter

C) 2012 American College of Nurse Practitioners

http://dx.doi.org/10.1016/j.nurpra.2012.05.019 